3. Dolgih T.I., Mironenko M.M., Shelev M.V. The etiological characteristics of infectious diseases of the perinatal period in the Omsk region. Jepidemiologiya i infektsionnye bolezni. 2011; 2 : 8-12. (in Russian)

4. Dolgih T.I., Shelev M.V., Minakova E.Ju., Prodanchuk E.G., Kadcyna T.V. The immunological aspects of infectious pathology. Medicinskaja immunologija. 2011; 13 (4-5): 423-4. (in Russian)

5. Kochorova L.V., Kolesnikova N.Ju. The organization of medical care to students - the mechanism of health protection of future generations. Vestnik Sankt-Peterburgskogo universiteta. Series 11. 2008; 1: 138-44. (in Russian)

6. Kupchinov R.I. The formation of healthy style of life of students Minsk: National educational institute; 2007. (in Russian)

7. Latyshevskaja N.I., Klauchek S.V., Moskalenko N.P. Gender distinctions in a state of health and quality of life of students. Gigiena i sanitarija. 2004; 1: 51-5. (in Russian)

8. Lukov V.A. Health of students in the light of a problem of human potential. In book: Works of the Second Vseros. scientific conference with international participation "Health $-\mathrm{a}$ basis of human potential: problems and ways of their decision". SPb.: Publishing house Polytechnic University. un-that; 2007: 123-5. (in Russian)

9. Savicheva A.M., Shipicyna E.V. Perinatal infections: problems and ways of their solution. Akusherstvo i ginekologija. 2009; 3 33-8. (in Russian)
10. Starodubov V.I., Suhanova L.P., Sychenkov Ju.G. Reproductive losses as a medical and social problem of demographic development of Russia. Electronic scientific journal "Social'nye aspekty zdorov'ja naselenija”. 2011; 6. Aviable at: http://vestnik. mednet.ru. (in Russian)

11. Shemetova G.N., Dudrova E. V. Problems of health of modern student's youth and unresolved questions of the organization of healingand preventive help. Saratovskij nauchno-medicinskij zhurnal. 2009; 5(4): 526-30. (in Russian)

Поступила 12.09 .13

\section{Авторская справка}

Сербаев Дмитрий Александрович, мл. науч. сотр. Центральной научно-исследовательской лаб. Омской государственной медицинской академии, e-mail: postovoi@yandex. ru; Кадиына Татьяна Владимировна, канд. мед. наук, ст. науч. сотр. Центральной научно-исследовательской лаб., ассистент каф. акушерства и гинекологии № 2 “Омской государственной медицинской академии, 644043, Омск, ул. Ленина, 12, e-mail: tatianavlad@list.ru; Чекмарев Герман Викторович, канд. мед. наук, ст. науч. сотр. Центральной научно-исследовательской лаб., ассистент каф. патологической физиологии “Омской государственной медицинской академии”, 644043, e-mail: gtchekmarev@narod.ru

\title{
ОБЗОРЫ
}

(с) КОЛЛЕКТИВ АВТОРОВ, 2014

УДК 579.25.083.1

О.С. Бондарева, С.С. Савченко, Г.А. Ткаченко, А.И. Абуева, Ю.О. Муратова, В.А. Антонов

\section{СОВРЕМЕННЫЕ ПОДХОДЫ К ГЕНОТИПИРОВАНИЮ ВОЗБУДИТЕЛЕЙ ОСОБО ОПАСНЫХ ИНФЕКЦИЙ}

ФКУЗ Волгоградский научно-исследовательский противочумный институт Роспотребнадзора, 400131, Волгоград, ул. Голубинская, 7

\begin{abstract}
В настоящее время генотипирование микроорганизмов широко используется в расследовании вспьшек инфекиионньх заболеваний, осуществлении эпидемиологического надзора за инфекичями, филогенетическом анализе бактериальных патогенов. Развитие методов генотипирования особенно актуально для возбудителей особо опасных инфекиии, таких как чума, холера, сибирская язва, бруиеллез, туляремия, сап и мелиоидоз, вследствие их высокой патогенности и контагиозности. В данном обзоре приведена характеристика различных методов генотипирования с указанием их преимушеств и недостатков. Проанализирована частота использования методов генотипирования по годам и в зависимости от вида возбудителя.

К л юч е в ы е с ло в а : генотипирование; особо опасная инфекция; рестрикиия; электрофорез; полимеразная иеепная реакиия; гибридизачия; секвенирование.
\end{abstract}

O. S. Bondareva, S. S. Savchenko, G. A. Tkachenko, A. I. Abueva, Yu. O. Muratova, V. A. Antonov MODERN APPROACHES TO GENOTYPING OF CAUSATIVE AGENTS OF PARTICULARLY DANGEROUS INFECTIONS

Research Institute for Plague Control of the Federal Service for Surveillance in the sphere of Consumers Rights Protection and Human Welfare, 7 , Golubinskaya Str., Volgograd, 400131, 400131, Volgograd, Russian Federation

Currently genotyping of microorganisms is widely used in the investigation of outbreaks of infectious diseases, the implementation of epidemiological surveillance of infections and phylogenetic analysis of bacterial pathogens. Development of methods for genotyping is particularly topical for pathogens of such highly dangerous infections as plague, cholera, anthrax, brucellosis, tularemia, glanders and melioidosis, due to their high pathogenicity and contagiousness. In this overview there is presented the characteristics of different genotyping methods together with an indication of their advantages and drawbacks. There has been analyzed the frequency of the use of genotyping methods on an annual basis and in terms of the type of the causative agents of especially dangerous infections.

Key words: genotyping; particularly dangerous infection; restriction analysis; electrophoresis; polymerase chain reaction; hybridization; sequencing.

Для корреспонденции: Бондарева Ольга Сергеевна, науч. сотр. лаб. генной диагностики и типирования микроорганизмов, е-таil: bondarevaOs@mail.ru 


\section{Введение}

Целью генотипирования является внутривидовая дифференциация микроорганизмов на основе различий их геномов. К задачам типирования относятся: расследование вспышек инфекционных заболеваний природного или техногенного характера, мониторинг природных очагов опасных инфекционных болезней, геномная паспортизация и определение филогенетических связей штаммов микроорганизмов. В настоящее время более 160 видов микроорганизмов считаются патогенными [1]. Наиболее пристального внимания заслуживают возбудители особо опасных инфекций (ООИ), потенциальные агенты биотерроризма, такие как Yersinia pestis, Vibrio cholerae, Bacillus anthracis, Brucella spp., Francisella tularensis, Burkholderia pseudomallei, Burkholderia mallei [2]. Заболевания, вызываемые данными патогенами, как правило, способны к эпидемическому распространению с охватом больших масс населения и характеризуются крайне тяжелым течением с высокой летальностью либо инвалидизацией переболевших.

В случае возникновения вспышек особо опасных инфекций большое значение имеют их своевременная диагностика и типирование патогенных биологических агентов для установления источника заражения, реализации необходимых мер защиты, устранения опасности дальнейшего распространения инфекции, лечения зараженных людей. Характеристиками оптимального метода типирования являются высокая дискриминирующая сила, позволяющая в идеале различать все исследуемые изоляты, а также высокая скорость получения результата, воспроизводимость, простота в исполнении, интерпретации и низкая себестоимость. К важным параметрам относятся возможность сопоставления результатов, полученных разными лабораториями, наличие общедоступных баз данных и международной номенклатуры [3].

На сегодняшний день разработано множество молекулярно-генетических методов, применяемых для изучения эпидемиологической характеристики бактериальных изолятов. Методы генотипирования можно объединить в следующие группы: 1) методы, включающие рестрикцию и электрофорез, 2) методы, основанные на амплификации вариабельных локусов, 3) методы, основанные на гибридизации, 4) методы, основанные на секвенировании.

\section{1. Методы, включающие рестрикцию и электро- форез}

Плазмидный анализ (ПА) используется в бактериологии уже много лет. В данном методе анализируют картину ДНК-паттернов, полученную при электрофорезе интакных плазмид или фрагментов, образованных после расщепления плазмидной ДНК эндонуклеазами рестрикции. Плазмиды как мобильные генетические элементы не являются стабильной характеристикой бактерий, могут спонтанно теряться/приобретаться, передаваться путем “горизонтального переноса” неродственным микроорганизмам. Плазмидный профиль является важной характеристикой штаммов Y. pestis, B. anthracis, V. cholerae $[4,5]$.

Пульс-электрофорез (ПЭФ) - метод фракционирования крупных молекул ДНК (от 5 тыс. п.н. до 10 млн. п.н.), полученных после рестрикции хромосом редкощепящей эндонуклеазой с помощью электрофореза в условиях периодически меняющегося по направлению (“"пульсирующего”) электрического поля. ПЭФ был и во многих случаях остается золотым стандартом типирования микроорганизмов, так как обладает высокой воспроизводимостью, дискриминирующей способностью, результаты типирования хорошо согласуются с эпидемиологическими данными, картины ДНК-паттернов легко интерпретируются. По данным A. Sabat. и соавт. [3] наибольшая доля статей по генотипированию посвящена использованию ПЭФ (более 2700 в базе данных PubMed). Широкому распространению метода на практике способствовала стандартизация, трактующая родство исследуемых штаммов по количеству отличающихся полос на электрофореграмме, предложенная F. Tenover и соавт. [6]. Стабильность результатов ПЭФ при соблюдении условий протокола позволила создать базы данных для большинства видов бактерий. Пульс-электрофорез отлично зарекомендовал себя при расследовании вспышек особо опасных инфекционных заболеваний [7], установлении филогенетических связей различных штаммов [8]. Часто данный метод используется в качестве стандарта генотипирования при разработке новых методов [9, 10]. К недостаткам пульс-электрофореза можно отнести трудоемкость, продолжительное время анализа (3-4 дня), а также возможность резкого изменения электрофоретического профиля даже изза одной мутации.

Полиморфизм длин рестрикиионных фрагментов (ПДРФ) основан на обработке тотальной ДНК, выделенной из культуры микроорганизмов, эндонуклеазами рестрикции, расщепляющими нуклеиновые кислоты в специфических “сайтах узнавания”. Образующиеся фрагменты ДНК отличаются по количеству и размерам у разных штаммов и анализируются с помощью гель-электрофореза. Данная методика проста в выполнении, однако в некоторых случаях получаемые картины ДНК-паттернов трудно интерпретировать вследствие большого количества рестрикционных фрагментов. Поэтому ПДРФ сочетают с гибридизацией с ДНК/РНК-зондами. Самыми распространенными мишенями для конструирования зондов являются рибосомальные гены, также описано использование инсерционных последовательностей (IS-элементов) $[11,12]$. Высокоэффективной оказалась схема типирования на основе ПДРФ с использованием зондов, комплементарных IS-элементам возбудителя чумы, предложенная G. Torrea и соавт. [12]. Однако риботипирование в последние годы применяется редко в связи с высокой трудоемкостью проведения анализа. 
Упрощение процедуры анализа возможно за счет использования автоматической станции для риботипирования, хотя это не гарантирует повышения силы дискриминации [13].

Полиморфизм длин амлифицированных фрагментов (ПДАФ) базируется на расщеплении геномной ДНК комбинацией двух рестриктаз, одна из которых является частощепящей, а другая - редкощепящей. В результате образуется большое количество фрагментов с “липкими концами”. Затем проводят их лигирование с короткими двухцепочечными фрагментами ДНК - адапторами, которые частично комплементарны сайту рестрикции. Образованные продукты амплифицируют с помощью праймеров, которые на 5'конце содержат последовательность адаптора, а на 3'конце - 1-3 дополнительных нуклеотида. Добавление этих нуклеотидов необходимо для уменьшения числа фрагментов, образующихся в ходе полимеразной цепной реакции (ПЦР), что делает интерпретацию ДНКпаттернов более легкой. Применение капиллярного электрофореза с флуоресцентно-меченными праймерами позволяет упростить анализ результатов [14].

Преимуществами ПДАФ являются высокая дискриминирующая способность, воспроизводимость результатов и сопоставимость данных, полученных в разных лабораториях. Данный метод успешно применяется для расследования вспышек особо опасных заболеваний, однако эффективность ПДАФ зависит от выбора адапторов, при недостаточной оптимизации он показывает меньшую разрешающую способность по сравнению с ПЭФ [14, 15]. К недостаткам метода можно отнести трудоемкость (анализ занимает около трех дней) и относительно высокую себестоимость вследствие необходимости использования коммерческих наборов реагентов (ферменты, адапторы, праймеры).

ПЦР с последующей рестрикичиеи продуктов амплификации (ПЦР-ПДРФ). В отличие от прямого ПДРФ на первом этапе в данном методе проводят амплификацию со специфическими праймерами, ограничивающими исследуемый участок ДНК. Затем с помощью эндонуклеаз рестрикции фрагмент гена расщепляется, а после проведения электрофореза изучаются полученные профили. Это позволяет сократить количество анализируемых фрагментов и облегчить интерпретацию результата, однако увеличивает время проведения анализа. В последние годы данный метод использовался редко. Дискриминирующая сила и воспроизводимость ПЦР-ПДРФ определяются выбором праймеров и рестриктаз. Так, использование данного метода F. Reen [16] для возбудителя холеры позволило провести идентификацию, но было неэффективно для внутривидовой дифференциации микроорганизма. Однако схема, предложенная N. Chowdhury [9], позволила разделить 94 штамма $V$. cholerae биовара Эль Тор, 29 штаммов $V$. cholerae классического биовара и 54 штамма $V$. cholerae O139 на 9, 3 и 6 групп соответственно, что сравнимо с результатами ПЭФ.

\section{2. Методы, основанные на амплификации вариа- бельных локусов}

Мультиплексная ПЦР - молекулярно-биологический метод, широко используемый в биологической и медицинской практике. При использовании в ПЦР в качестве мишеней генов патогенности, может быть получена клинически значимая характеристика штаммов. Также данная процедура проста в исполнении и легко интерпретируема. В качестве ДНК-мишеней часто используются гены «домашнего хозяйства», например алгоритм типирования возбудителя чумы, предложенный Г.А. Ерошенко и соавт. [17], включает определение наличия генов жизнеобеспечения (terC, ilvN, inv, glpD, nap A, rhaS и $\operatorname{ara} C)$. Другими часто используемыми мишенями в ПЦР-типировании являются гены антибиотикорезистентности [18], а также гены, кодирующие факторы вирулентности. Определение генов токсичности и патогенности является важным этапом характеристики штаммов $V$. cholerae, анализируют такие гены, как toxR, hlyA, ctxA, zot, ace, tcpA, stn, tox T [19].

Технология MGB-зондов (taqman-minor groove binding - модифицированные зонды с повышенной температурой отжига) позволяет использовать ПЦР для определения однонуклеотидного полиморфизма (SNP - single nucleotide polymorphism). C помощью данного метода были определены наиболее эффективные SNP-локусы для типирования микроорганизма $B$. anthracis, геном которого характеризуется выраженной консервативностью [20].

DFR-анализ (different region - DFR). Метод амплификации дифференцирующих фрагментов генома заключается в серии ПЦР с праймерами, фланкирующими фрагменты ДНК-мишеней, присутствующих только у определенных штаммов. Преимуществами данного метода является легкость интерпретации, использование стандартного оборудования, быстрота получения результата. Недостатком является необходимость проведения большого количества параллельных реакций амплификации, поскольку разрешающая сила метода зависит от количества выбранных локусов.

Схема генотипирования Y. pestis на основе 23 DFRлокусов, предложенная Y. Li и соавт. [21], показала, что на территории природных очагов Китая циркулируют штаммы 32 типов, причем для каждого очага характерен свой основной DFR-тип. DFR-анализ еще не получил широкого распространения, не разработана единая терминология. Так, алгоритм типирования на основе 14 локусов, предложенный K. Duangsonk и соавт. [22] для возбудителя мелиоидоза, разделивший 98 изолятов $B$. pseudomallei на 59 генотипов, назывался VAT-анализ (variable amplicon typing), а схема, включающая 19 пар праймеров, подобранных на регионы дифференциально присутствующие у различных возбудителей бруцеллеза, отнесена к ПЦР [23].

ПЦР с произвольными праймерами, RAPD (random amplified polymorphic DNA). Метод RAPD осно- 
ван на использовании произвольных олигонуклеотидных праймеров длиной 9-10 нуклеотидов, которые отжигаются при низкой температуре на большом количестве сайтов в различных областях генома, что инициирует амплификацию анонимных последовательностей ДНК разной длины. RAPD-типирование - относительно нетрудоемкий и быстрый метод, не требующий подбора специфических праймеров, с низкой себестоимостью и высокой разрешающей способностью.

Для возбудителя сапа разработана схема типирования на основе 6 олигонуклеотидов, позволившая разделить 14 исследуемых штаммов на отдельные RAPD-типы [24]. ПЦР с произвольными праймерами успешно применена для типирования возбудителя холеры, выявлено значительное генетическое разнообразие слабопатогенных штаммов $V$. cholerae различных серогрупп [25].

Основным недостатком ПЦР с произвольными праймерами является низкая межлабораторная воспроизводимость, так как полученный результат зависит от целостности выделенной ДНК, режима и условий проведения ПЦР, что проявляется в изменении RAPD-паттернов.

ПЦР с праймерами на IS-элементы и повторяющилеся элементы, rep-PCR. В данном случае амплификация проводится с праймерами к консенсусной последовательности повторяющихся элементов, рассеянных по геному. Совокупность амплифицированных последовательностей различной длины, заключенных между повторами, анализируется с помощью электрофореза. Среди повторяющихся нуклеотидных последовательностей можно выделить 3 группы: экстрагенные повторяющиеся палиндромы длиной 35-40 п.н. REP (repetitive extragenic palindromes), повторяющиеся межгенные последовательности длиной 124-127 П.н. ERIC (enterobacterial repetitive intergenic consensus) и ВОХ-элементы длиной 154 п.н. энтеробактерий и стрептококков. При сравнении методов REP, ERIC и RAPD для типирования штаммов F. tularensis REP и ERIC продемонстрировали меньшую разрешающую силу, однако большую воспроизводимость [26]. Анализ использования данных подходов для типирования V. cholerae показал возможность применения ПЦР с праймерами на повторяющиеся элементы для дифференциации штаммов $V$. cholerae не O1-й/не O139-й группы, a наибольшей дискриминирующей силой обладал метод ERIC-ПЦР [27]. Было показано, что при дифференциации Y. pestis с помощью ERIC-ПЦР образуются группы, сходные с MLVA-профилем, что говорит о возможности использования данного метода в эпидемиологическом исследовании чумы [28].

IS-элементы относятся к простым мобильным генетическим элементам и используются для типирования многих возбудителей ООИ. Типирование 77 штаммов возбудителя чумы и 2 штаммов псевдотуберкулеза с использованием праймеров к IS100 позволило разделить исследуемые микроорганизмы на 16 IS-типов [29]. IS-типирование F. tularensis позволило дифференцировать штаммы внутри групп AI и AII, однако штаммы группы В принадлежали к одному генотипу [30].

Также к типированию на основе ПЦР с праймерами на повторяющиеся элементы можно отнести CRISPR-анализ. CRISPR-элементы (CRISPR - clustered regularly interspaced short palindromic repeats) представляют собой короткие палиндромные повторы, регулярно расположенные группами, длиной 24-48 п.н. CRISPR-типирование возбудителя чумы, предложенное Y. Cui и соавт. [31], показало зависимость между отдельными типами спейсеров и географическим происхождением исследуемых штаммов. Недостатком метода является необходимость секвенирования для выявления незначительных различий в последовательностях CRISPR-спейсеров [32].

Несмотря на то, что данная группа методов нуждается в стандартизации, в целом ПЦР с праймерами на IS-элементы и повторяющиеся элементы характеризуется хорошей воспроизводимостью, разрешающей силой, сопоставимой с ПЭФ, легкостью проведения анализа и быстротой.

Мультилокусный анализ числа вариабельных тандемных повторов, MLVA (multiple-locus variable number tandem repeat analysis). Принцип метода MLVA заключается в выявлении тандемно расположенных повторяющихся последовательностей, число повторов которых варьирует у различных штаммов. Тандемные повторы (VNTR - variable number tandem repeat) в зависимости от размера можно разделить на классы: VNTR (более 7 нуклеотидов), SSR/STR (simple sequence repeat/short tandem repeat 2-6 нуклеотидов), SNR (single nucleotide repeat - однонуклеотидные повторы). К MLVA-типированию относят использование первых двух типов повторов, определение количества однонуклеотидных повторов чаще выделяют в отдельный метод SNRанализ. Существует несколько технических исполнений анализа тандемных повторов: с использованием электрофореза в агарозном или полиакриламидном геле, а также с применением капиллярного гель-электрофореза в автоматических анализаторах. Первый подход проще и доступнее [33], однако второй более точен, особенно при анализе коротких повторов (STR) [34]. При использовании различных флуоресцентных меток за один запуск на автоматическом анализаторе можно независимо определять длину сразу нескольких ампликонов [35]. Секвенирование ампликонов дает более точные результаты, исключает погрешность, вызванную мутациями внутри VNTR-локуса, однако себестоимость анализа многократно увеличивается [3, 34].

На сегодняшний день метод MLVA наиболее часто применяется для типирования возбудителей ООИ, показывая высокую дифференцирующую способность, а также, что более важно, корреляцию образуемых групп с географической и иной 
приуроченностью [36-38]. Дискриминирующая сила данного метода превосходит пульс-электрофорез и многие другие методы, часто позволяя разделить практически все исследуемые штаммы на отдельные MLVA-типы $[39,40]$. SNR-анализ показал наибольшую эффективность при типировании $B$. anthracis за счет высокой мутабельности однонуклеотидных повторов [41]. Метод анализа тандемных повторов нуждается в стандартизации, и на данном этапе еще ведутся работы по выбору наиболее эффективных VNTR-локусов [35], также необходимо расширение спектра микроорганизмов в базах данных сети интернет.

Анализ кривых плавления, HRM (high-resolution melting analysis), основан на мониторинге в реальном времени процесса плавления амплифицированных фрагментов ДНК. При нагревании двухцепочечная ДНК денатурирует и происходит высвобождение интеркалирующих красителей, что проявляется снижением уровня флюоресценции. HRM-профиль зависит от длины и ГЦ-состава ампликонов, и при определенных условиях даже однонуклеотидная замена отражается на форме кривой плавления. Быстрота и высокая чувствительность данного метода объясняют его популярность для выявления SNP [42]. Было показано, что HRM также обеспечивает быструю, надежную и недорогую идентификацию и дифференциацию штаммов рода Brucella, схема из семи пар праймеров позволила разделить исследуемые штаммы с 99\% точностью по сравнению с классическими методами [43]. HRM-анализ на основе генов $\beta$-лактамаз был предложен для молекулярного типирования патогенных видов Burkholderia [44]. А. Ciammaruconi и соавт. [45] показали, что HRM может дополнить MLVA-типирование $Y$. pestis путем разделения ампликонов с различным числом тандемных повторов быстрее и при более низкой стоимости. Данный метод широко не используется, поскольку требует тщательной оптимизации праймеров и условий, а без стандартизации обмен результатами между лабораториями ограничен.

\section{3. Методы, основанные на гибридизации}

В данный момент наиболее востребованным методом на основе гибридизации является технология микроэрреев. ДНК-микроэррей (ДНК-микрочип, биочип) представляет собой подложку, на которую в виде дискретных точек иммобилизовано большое количество ДНК-зондов. Процесс применения биочипов включает несколько этапов: обработку образца, ДНК - ДНК-гибридизацию, детекцию и анализ результатов. На основе размера точек ДНК-эрреи делятся на микроэрреи (меньше 200 мкм) и макроэрреи (более 300 мкм). В качестве зондов в биочипах могут выступать кДНК (такие чипы могут быть использованы для сравнительной геномной гибридизации) или олигонуклеотидные зонды (чаще используются для SNP-типирования) [46].

Технология микрочипов дает возможность одно- временного анализа огромного количества различных ДНК-последовательностей, позволяя проводить детекцию и дифференциацию нескольких микроорганизмов. Например, Y. Yang и соавт. [4] разработали 2 варианта чипов для обнаружения B. anthracis, Y. pestis, Brucella spp., F. tularensis, B. pseudomallei: с универсальными праймерами к гену $16 \mathrm{~S}$ рРНК и мультиплексный вариант с видоспецифическими праймерами. Биочипы успешно используются для филогенетического анализа и SNP-типирования, в работе G. Pandya и соавт. [47] анализ 40 штаммов $F$. tularensis различных подвидов, проведенный с помощью микроэрреев для секвенирования (resequencing array), позволил выбрать SNP с наибольшей разрешающей силой.

К недостаткам ДНК-микрочипов можно отнести трудности по контролю качества гибридизации каждой ДНК-мишени, необходимость применения сложных статистических алгоритмов и методов нормализации анализа данных [4]. Высокая стоимость оборудования и расходных материалов препятствует использованию данной технологии для рутинного генотипирования ООИ, несмотря на их преимущества.

\section{4. Методы, основанные на секвенировании}

Секвенирование - метод, основанный на определении нуклеотидной последовательности исследуемого фрагмента генома. Данные секвенирования однозначны, легко поддаются интерпретации, метод обладает высокой точностью, воспроизводимостью, а также универсальностью. Однако, несмотря на ежегодное снижение себестоимости анализа, цена остается все еще достаточно высокой.

Для стандартизации результатов типирования $\mathrm{M}$. Maiden и соавт. [48] предложили метод мультилокусного сиквенс-типирования (MLST - multiLocus sequence typing), в котором анализируется 6-14 генов “домашнего хозяйства". К настоящему моменту в базах данных (www.mlst.net, www.pubmlst.org) представлены результаты MLST-типирования $V$. cholerae, B. pseudomallei, Yersinia spp. и др. Генотипирование на основе секвенирования генов “домашнего хозяйства" наиболее эффективно для эпидемиологического анализа штаммов возбудителя холеры. В серии публикаций по типированию возбудителя чумы описано использование различных наборов генов, как генов «домашнего хозяйства», так и генов вирулентности (cafl, lcrV, psaA, pla) [32, 49]. Несмотря на обнаружение определенного полиморфизма, в целом метод обладал недостаточной разрешающей силой, уступая ПЭФ [49]. Для некоторых микроорганизмов метод MLST оказался малоэффективным. У возбудителя сапа было зарегистрировано всего лишь два сиквенс-типа (www.mlst.net), а $B$. anthracis часто образуют единый клональный комплекс со штаммами из группы cereus [50].

Иногда для анализа достаточно секвенирования одного полиморфного гена, такого как ген $r p o B$ возбудителя бруцеллеза [51]. Однако разрешающая 
способность метода увеличивается при возрастании размера и количества анализируемых фрагментов. Для сиквенс-типирования холерных вибрионов с успехом используются межгенный спейсер $16 \mathrm{~S}-23 \mathrm{~S}$ рРНК, мобильные генетические элементы и гены патогенности $[52,53]$. Другой часто анализируемой ДНК-мишенью является однонуклеотидный полиморфизм [51]. Так, набор канонических SNP был использован для филогенетического анализа штаммов сибирской язвы из Свердловска [54].

В последние годы помимо увеличения частоты использования стандартных протоколов секвенирования, разрабатываются новые методики, например пиросеквенирование [55], также все больше публикаций посвящено использованию массового параллельного секвенирования (next-generation sequencing) для расшифровки последовательности всего микробного генома. При этом полногеномное секвенирование все чаще не только способствует пониманию механизмов патогенности возбудителей или обеспечивает базу для развития других методов типирования, но и самостоятельно выступает в роли метода генотипирования в эпидемиологических и даже судебно-медицинских расследованиях $[56,57]$.

\section{Выбор оптимального метода генотипирования}

Для анализа частоты применения различных методов генотипирования возбудителей ООИ и определения наиболее актуальных молекулярнобиологических подходов мы рассматривали статьи, опубликованные с 1 января 2004 г. по 30 июня 2013 г., представленные в электронных базах данных (http://www.ncbi.nlm.nih.gov/pubmed, highwire. stanford.edu//, http://elibrary.ru). Одним из наиболее важных критериев выбора метода генотипирования является дискриминирующая сила - способность различать бактериальные штаммы одного вида. Как правило, методы анализа быстро эволюционирующих маркеров, такие как MLVA, HRM, обладают большей эффективностью дискриминации, чем те, которые опираются на более консервативные маркеры, например MLST. Методы типирования на основе анализа всего генома (ПЭФ, ПДАФ, ПДРФ, геномные микроэрреи, полногеномное секвенирование) характеризуются большей разрешающей силой, чем методы типирования, анализирующие ограниченное количество локусов (риботипирование, ПЦРПДРФ, MLST). Тем не менее дискриминирующая способность зависит от многих факторов, таких как используемые ферменты и праймеры, условия амплификации. Большинство методов генотипирования характеризуются различной дискриминирующей силой в зависимости от анализируемого вида микроорганизма.

Для микроорганизмов с выраженной клональностью, таких как возбудители сибирской язвы, бруцеллеза, методы генотипирования на основе анализа консервативных маркеров (гены “домашнего хозяйства”, рРНК) неэффективны. Поэтому в большин-

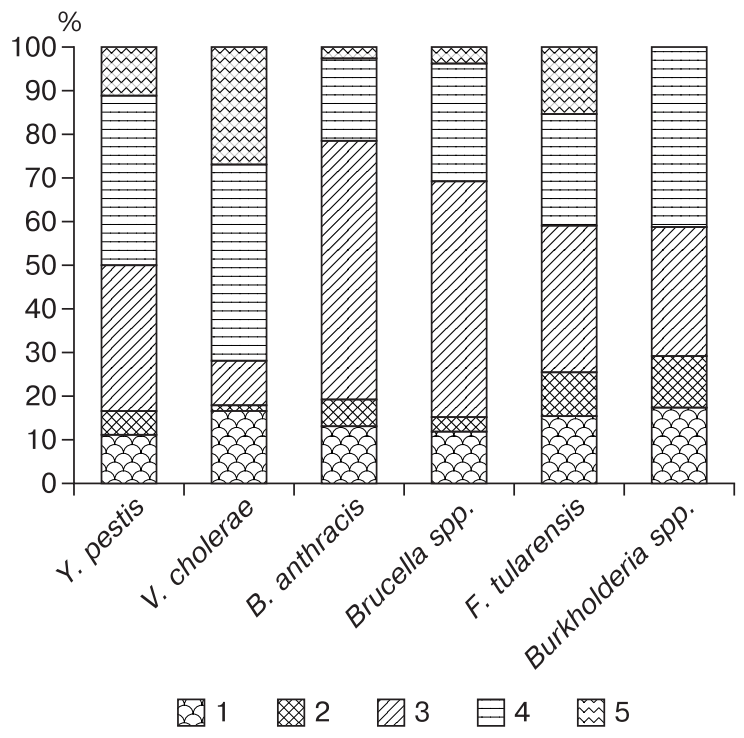

Рис. 1. Распределение частоты использования методов генотипирования для различных возбудителей ООИ. Общее количество публикаций по Y. pestis - 36, V. cholerae - 243, B. anthracis -47 , Brucella spp. $-85, F$. tularensis -39 , Burkholderia spp. -17 .

1 - методы, включающие рестрикцию и электрофорез; 2 - методы, основанные на амплификации вариабельных локусов; 3 - мультилокусный анализ вариабельных тандемных повторов; 4 - методы, основанные на гибридизации; 5 - методы, основанные на секвенировании.

стве публикаций по типированию данных возбудителей описано использование таких маркеров, как VNTR, SNR, SNP (рис. 1).

Полиморфность геномов $V$. cholerae, B. pseudomallei и Y. pestis облегчает типирование данных микроорганизмов, для них разработано и применяется большинство известных методов. Накопленная за многие годы информация по типированию с помощью пульс-электрофореза объясняет значительную долю публикаций по использованию данного метода для анализа возбудителя холеры.

Анализ распределения публикаций по годам позволил проследить динамику использования различных методов генотипирования (рис. 2).

Для наглядности результаты по мультилокусному анализу числа вариабельных тандемных повторов представлены отдельно, поскольку по данному методу начиная с 2006 г. публиковалось наибольшее количество статей. Сравнение количества публикаций за 2010-2012 гг. с аналогичным периодом за 2007-2009 гг. показало рост публикационной активности по методам на основе амплификации вариабельных локусов. В наибольшей степени интерес возрос к группе методов, основанных на секвенировании. Универсальность данного подхода, отраженная в примерно равных долях публикаций, посвященных его использованию у всех исследуемых микроорганизмов (см. рис. 1), развитие новых методик секвенирования, экспоненциальное снижение себестоимости позволяют предположить, что в будущем данная технология выйдет на первое место среди методов типирования. 


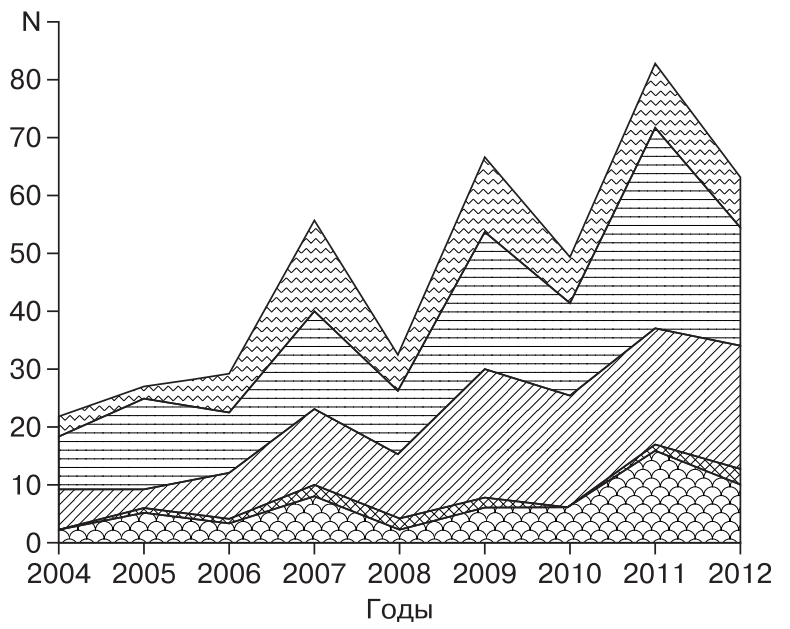

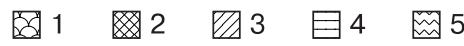

Рис. 2. Распределение публикаций, посвященных использованию различных методов генотипирования, по годам. $N$ количество опубликованных статей, ширина заштрихованного сектора определяет число публикаций.

1 - методы, включающие рестрикцию и электрофорез; 2 - методы, основанные на амплификации вариабельных локусов; 3 - мультилокусный анализ вариабельных тандемных повторов; 4 - методы, основанные на гибридизации; 5 - методы, основанные на секвенировании.

\section{Заключение}

В последние годы методы генотипирования претерпели существенные изменения: возрос уровень автоматизации, повысилась дискриминирующая сила и пропускная способность, разработаны адекватные средства биоинформатики. Постоянный рост баз данных, содержащих последовательности ДНК и профили типирования, позволяет проще и быстрее проводить сопоставление результатов из разных лабораторий, осуществлять ретроспективный анализ, долгосрочный эпидемиологический надзор за ООИ. К сожалению, в настоящее время нет идеального метода типирования, каждый подход имеет ряд преимуществ и недостатков. Подходящий метод следует выбирать в зависимости от цели, если важна скорость анализа, как в случае определения источника вспышки инфекции, предпочтительны методы на основе амплификации вариабельных локусов, например MLVA, DFR. С целью проведения филогенетического анализа для сопоставления результатов с предыдущими исследованиями используют ПЭФ, MLST. Наибольшей информативностью обладает метод полногеномного секвенирования, однако он все еще имеет высокую себестоимость, а анализ результатов занимает очень длительное время. Таким образом, на данном этапе развития методов генотипирования оптимальным под- ходом является сочетание методов анализа локусов с различной степенью полиморфизма, что обеспечит высокую достоверность результатов и точность дискриминации бактериальных штаммов.

\section{Словарь терминов и сокращений}

CRISPR (clustered regularly interspaced short palindromic repeats) - короткие палиндромные повторы, регулярно расположенные группами

DFR-анализ (different region) - метод амплификации дифференцирующих фрагментов генома

HRM (high-resolution melting analysis) - анализ кривых плавления высокого разрешения

MLST (multiLocus sequence typing) - мультилокусное сиквенс-типирование

MLVA (multiple-locus variable number tandem repeat analysis) - мультилокусный анализ числа вариабельных тандемных повторов

NGS (next-generation sequencing) - массовое параллельное (полногеномное) секвенирование

RAPD (random amplified polymorphic DNA) ПЦР с произвольными праймерами

Rep-ПЦР - ПЦР с праймерами на повторяющиеся элементы генома

SNP (single nucleotide polymorphism) - однонуклеотидный полиморфизм

SNR (single nucleotide repeat) - однонуклеотидные повторы

VNTR (variable number tandem repeat) - вариабельные тандемные повторы

ПА - плазмидный анализ

ПДАФ - полиморфизм длин амплифицированных фрагментов

ПДРФ - полиморфизм длин рестрикционных фрагментов

ПЭФ - пульс-электрофорез

Та блица 2

Сравнение методов генотипирования возбудителей особо опасных инфекций

\begin{tabular}{l|c|c|c|c|c|c}
\hline Метод & $\begin{array}{c}\text { Дискрими- } \\
\text { нирующая } \\
\text { сила }\end{array}$ & $\begin{array}{c}\text { Воспро- } \\
\text { изводи- } \\
\text { мость }\end{array}$ & $\begin{array}{c}\text { Простота } \\
\text { проведения } \\
\text { анализа }\end{array}$ & $\begin{array}{c}\text { Легкость } \\
\text { интерпре- } \\
\text { тации }\end{array}$ & $\begin{array}{c}\text { Ско- } \\
\text { рость } \\
\text { анализа }\end{array}$ & $\begin{array}{c}\text { Экономи- } \\
\text { ческая до- } \\
\text { ступность }\end{array}$ \\
\hline ПА & ++ & ++ & ++ & +++ & ++ & +++ \\
ПЭФ & +++ & +++ & $+/++$ & ++ & + & ++ \\
ПДРФ & ++ & +++ & +++ & + & ++ & +++ \\
ПЦР-ПДРФ & ++ & +++ & ++ & $++/+++$ & ++ & ++ \\
ПДАФ & +++ & +++ & + & ++ & ++ & ++ \\
DFR & ++ & +++ & +++ & +++ & +++ & +++ \\
RAPD & +++ & + & +++ & + & +++ & +++ \\
Rep-PCR & ++ & ++ & +++ & $++/+++$ & +++ & +++ \\
MLVA & +++ & +++ & ++ & ++ & +++ & ++ \\
HRM & +++ & ++ & +++ & +++ & +++ & ++ \\
Биочипы & +++ & +++ & $+/++$ & ++ & ++ & + \\
MLST & ++ & +++ & + & ++ & ++ & + \\
NGS & +++ & +++ & + & ++ & + & +
\end{tabular}

П р и м е ч а н и е . "+" - низкая, "++" - умеренная, "+++" - высокая. 
Спейсер - нетранскрибируемая последовательность ДНК, расположенная между повторяющимися элементами генома

\section{Л И ТЕ РАТ У РА}

1. Yang Y., Wang J., Wen H., Liu H. Comparison of two suspension arrays for simultaneous detection of five biothreat bacterial in powder samples. J. Biomed. Biotechnol. 2012; 2012: 831052.

2. Мартынюк Р.А., Сандахчиев Л.С., Нетесов С.В., Онищенко Г.Г. Биотерроризм: национальная и глобальная угроза. Вестник Российской АН. 2003; 3: 195.

3. Sabat A.J., Budimir A., Nashev D., Sá-Leão R., van Dijl Jm, Laurent $\boldsymbol{F}$. et al. Overview of molecular typing methods for outbreak detection and epidemiological surveillance. Euro Surveill. 2013; 18(4): 20380.

4. Бренева Н.В., Марамович А.С., Климов В.Т. Популяционная изменчивость Yersinia pestis в почве из природного очага чумы. Журнал микробиологии, эпидемиологии и иммунобиологии. 2006; 2: 7-11.

5. Mwansa J.C., Mwaba J., Lukwesa C., Bhuiyan N.A., Ansaruzzaman M., Ramamurthy T. et al. Multiply antibiotic-resistant Vibrio cholerae $\mathrm{O} 1$ biotype El Tor strains emerge during cholera outbreaks in Zambia. Epidemiol. Infect. 2007; 135(5): 847-53.

6. Tenover F.C., Arbeit R.D., Goering R.V., Mickelsen P.A., Murray B.E., Persing $\boldsymbol{D}$.H. et al. Interpreting chromosomal DNA restriction patterns produced by pulsed-field gel electrophoresis: criteria for bacterial strain typing. J. Clin. Microbiol. 1995; 33(9): 2233-9.

7. Smith A.M., Keddy K.H., De Wee L. Characterization of cholera outbreak isolates from Namibia, December 2006 to February 2007. Epidemiol. Infect. 2008; 136(9): 1207-9.

8. Safa A., Bhuiyan N.A., Alam M., Sack D.A., Nair G.B. Genomic relatedness of the new Matlab variants of Vibrio cholerae O1 to the classical and El Tor biotypes as determined by pulsed-field gel electrophoresis. J. Clin. Microbiol. 2005; 43(3): 1401-4.

9. Chowdhury N., Asakura M., Neogi S.B., Hinenoya A., Haldar S., Ramamurthy T. et al. Development of simple and rapid PCR-fingerprinting methods for Vibrio cholerae on the basis of genetic diversity of the superintegron. J. Appl. Microbiol. 2010; 109(1): 304-12.

10. Li Z.J., Cui B.Y., Chen H., Chen J.D., Zhao H.Y., Piao D.R. et al. Molecular typing of Brucella suis collected from 1960s to 2010 s in China by MLVA and PFGE. Biomed. Environ. Sci. 2013; 26(6): 504-8.

11. Ерошенко Г.А., Павлова А.И., Куклева Л.М., Шавина Н.Ю., Кутырев В.В. Генотипирование штаммов Yersinia pestis на основе вариабельности генов биосинтеза рРНК. Журнал микробиологии, эпидемиологии и иммунобиологии. 2007; 3: 6-10.

12. Torrea G., Chenal-Francisque V., Leclercq A., Carniel E. Efficient tracing of global isolates of Yersinia pestis by restriction fragment length polymorphism analysis using three insertion sequences as probes. J. Clin. Microbiol. 2006; 44(6): 2084-92.

13. Fey P.D., Dempsey M.M., Olson M.E., Chrustowski M.S., Engle J.L., Jay J.J. et al. Molecular analysis of Francisella tularensis subspecies tularensis and holarctica. Am. J. Clin. Pathol. 2007; 128(6): 926-35.

14. Kantardjiev T., Ivanov I., Velinov T., Padeshki P., Popov B., Nenova R., Mincheff M. Tularemia outbreak, Bulgaria, 19972005. Emerg. Infect. Dis. 2006; 12(4): 678-80.

15. Zhou H., Lou J., Diao B., Cui Z., Pang B., Zhang L. et al. Comparison of amplified fragment length polymorphism and pulsedfield gel electrophoresis for subtyping of Vibrio cholerae serogroups O1 and O139. Foodborne Pathog, Dis. 2011; 8(2): 291-8.

16. Reen F.J., Boyd E.F. Molecular typing of epidemic and nonepidemic Vibrio cholerae isolates and differentiation of V. cholerae and $\mathrm{V}$. mimicus isolates by PCR-single-strand conformation polymorphism analysis. J. Appl. Microbiol. 2005; 98(3): 544-55.

17. Ерошенко Г.А., Одиноков Г.Н., Куклева Л.М., Павлова А.И., Краснов Я.М., Шавина Н.Ю. и др. Стандартный алгоритм молекулярного типирования штаммовYersinia pestis. Журнал микробиологии, эпидемиологии и иммунобиологии. 2012; 3: 25-35.

18. Романова А.В., Захарова И.Б., Замараев В.С., Викторов Д.В. Конструирование праймеров для детекции и типирования генов $\beta$-лактамаз патогенных видов рода Burkholderia.
Проблемы особо опасных инфекций. 2012; 2(112): 59-61.

19. Ломов Ю.М., Телесманич Н.Р., Кругликов В.Д., Авдеева Е.П., Ежсова М.И., Шалу О.А. и др. Фенотипическая и молекулярно-биологическая характеристика штаммов холерных вибрионов Эль-Тор, выделенных из водных объектов окружающей среды Ростова-на-Дону в 2003-2008 гг. Эпидемиология и инфекционные болезни. 2011; $1: 24-8$.

20. Van Ert M.N., Easterday W.R., Simonson T.S., U'Ren J.M., Pearson T., Kenefic L.J. et al. Strain-specific single-nucleotide polymorphism assays for the Bacillus anthracis Ames strain. J. Clin. Microbiol. 2007; 45(1): 47-53.

21. Li Y., Dai E., Cui Y., Li M., Zhang Y., Wu M. et al. Different region analysis for genotyping Yersinia pestis isolates from China. PLoS One. 2008; 3(5): e2166.

22. Duangsonk K., Gal D., Mayo M. et al. Use of a variable amplicon typing scheme reveals considerable variation in the accessory genomes of isolates of Burkholderia pseudomallei. J. Clin. Microbiol. 2006; 44(4): 1323-34.

23. Huber B., Scholz H.C., Lucero N., Busse H.J. Development of a PCR assay for typing and subtyping of Brucella species. Int. J. Med. Microbiol. 2009; 299(8): 563-73.

24. Antonov V.A., Tkachenko G.A., Altukhova V.V., Savchenko S.S., Zinchenko O.V., Viktorov D.V. et al. Molecular identification and typing of Burkholderia pseudomallei and Burkholderia mallei: when is enough enough? Trans. Roy. Soc. Trop. Med. Hyg. 2008; 102 (Suppl. 1): S134-9.

25. Ерошенко Г.A. Молекулярное типирование штаммов Vibrio cholerae не О1/ не О139, выделенных на территории российской федерации и других стран СНГ от больных людей. Проблемы особо опасных инфекций. 2005; 2(90): 64.

26. de la Puente-Redondo V.A., del Blanco N.G., Gutiérrez-Martín C.B., García-Peña F.J., Rodríguez Ferri E.F. Comparison of different PCR approaches for typing of Francisella tularensis strains. J. Clin. Microbiol. 2000; 38(3): 1016-22.

27. Shuan Ju Teh C., Thong K.L., Osawa R., Heng Chua K. Comparative PCR-based fingerprinting of Vibrio cholerae isolated in Malaysia. J. Gen. Appl. Microbiol. 2011; 57(1): 19-26.

28. Kingston J.J., Tuteja U., Kapil M., Murali H.S., Batra H.V. Genotyping of Indian Yersinia pestis strains by MLVA and repetitive DNA sequence based PCRs. Antonie v. Leeuwenhoek. 2009; 96(3): 303-12.

29. Motin V.L., Georgescu A.M., Elliott J.M., Hu P., Worsham P.L., Ott L.L. et al. Genetic variability of Yersinia pestis isolates as predicted by PCR-based IS100 genotyping and analysis of structural genes encoding glycerol-3-phosphate dehydrogenase (glpD). J. Bacteriol. 2002; 184(4): 1019-27.

30. Larson M.A., Fey P.D., Bartling A.M., Iwen P.C., Dempsey M.P., Francesconi S.C. et al. Francisella tularensis molecular typing using differential insertion sequence amplification. J. Clin. Microbiol. 2011; 49(8): 2786-97.

31. Cui Y., Li Y., Gorgé O., Platonov M.E., Yan Y., Guo Z. et al. Insight into microevolution of Yersinia pestis by clustered regularly interspaced short palindromic repeats. PLoS One. 2008; 3(7): e2652.

32. Платонов М.Е., Евсеева В.В., Дентовская С.В., Анисимов A.П. Молекулярное типирование Yersinia pestis. Молекулярная генетика, микробиология и вирусология. 2013; 2: 3-12.

33. Рязанова А.Г., Еременко Е.И., Цыганкова О.И., Цыганкова $\boldsymbol{E} . \boldsymbol{A . , ~ К у л и ч е н к о ~} \boldsymbol{A . H}$. Использование методов молекулярного типирования Bacillus anthracis в референс-центре по мониторингу за возбудителем сибирской язвы. Проблемы особо опасных инфекций. 2011; 4(110): 68-70.

34. Danin-Poleg Y., Cohen L.A., Gancz H., Broza Y.Y., Goldshmidt $\boldsymbol{H}$., Malul E. et al. Vibrio cholerae strain typing and phylogeny study based on simple sequence repeats. J. Clin. Microbiol. 2007; 45(3): $736-46$.

35. Vogler A.J., Birdsell D., Wagner D.M., Keim P. An optimized, multiplexed multi-locus variable-number tandem repeat analysis system for genotyping Francisella tularensis. Lett. Appl. Microbiol. 2009; 48(1): 140-4.

36. Кулаков Ю.К.,ЦирельсонЛ.Е., Желудков М.М. Молекулярногенетическая характеристика изолятов бруцелл, выделенных от собак и оленей в различных регионах России. Молекулярная генетика, микробиология и вирусология. 2012; 4: 28-33. 
37. Водопьянов А.С., Мишанькин Б.Н., Павлович Н.В., Пичурина Н.Л. Генотипическая гетерогенность и географическое разнообразие коллекционных штаммов Francisella tularensis по данным VNTR-анализа их ДНК. Молекулярная генетика, микробиология и вирусология. 2007; 2: 33-40.

38. Онищенко Г.Г., Куличенко А.Н., Рязанова А.Г., Демина Ю.В., Крига A.C., Еременко Е.И. и др. Анализ вспышки сибирской язвы в Омской области в 2010 г. Журнал микробиологии, эпидемиологии и иммунобиологии. 2012; 5: 33-6.

39. Lam C., Octavia S., Reeves P.R., Lan R. Multi-locus variable number tandem repeat analysis of 7 th pandemic Vibrio cholerae. BMC Microbiol. 2012; 12: 82 .

40. Price E.P., Hornstra H.M., Limmathurotsakul D., Max T.L., Sarovich D.S., Vogler A.J. et al. Within-host evolution of Burkholderia pseudomallei in four cases of acute melioidosis. PLoS Pathog. 2010; 6(1): e1000725.

41. Kenefic L.J., Beaudry J., Trim C., Daly R., Parmar R., Zanecki $S$. et al. High resolution genotyping of Bacillus anthracis outbreak strains using four highly mutable single nucleotide repeat markers. Lett. Appl. Microbiol. 2008; 46(5): 600-3.

42. Derzelle S., Laroche S., Le Flèche P., Hauck Y., Thierry S., Vergnaud $\boldsymbol{G}$. et al. Characterization of genetic diversity of Bacillus anthracis in France by using high-resolution melting assays and multilocus variable-number tandem-repeat analysis. J. Clin. Microbiol. 2011; 49(12): 4286-92.

43. Winchell J.M., Wolff B.J., Tiller R., Bowen M.D., Hoffmaster A.R. Rapid identification and discrimination of Brucella isolates by use of real-time PCR and high-resolution melt analysis. J. Clin. Microbiol. 2010; 48(3): 697-702.

44. Захарова И.Б., Романова А.В., Тетерятникова Н.Н., Замараев В.С., Викторов Д.В. Молекулярное типирование и анализ полиморфизма генов $\beta$-лактамаз патогенных видов Burkholderia. Вестник Волгоградского государственного медицинского университета. 2012; 2: 98-101.

45. Ciammaruconi A., Grassi S., Faggioni G., De Santis R., Pittiglio $\boldsymbol{V}$., $\boldsymbol{D}$ 'Amelio $\boldsymbol{R}$. et al. A rapid allele variant discrimination method for Yersinia pestis strains based on high-resolution melting curve analysis. Diagn. Microbiol. Infect. Dis. 2009; 65(1): 7-13.

46. Li W., Raoult D., Fournier P. Bacterial strain typing in the genomic era. FEMS Microbiol. Rev. 2009; 33: 892-916.

47. Pandya G.A., Holmes M.H., Petersen J.M., Pradhan S., Karamycheva S.A., Wolcott M.J. et al. Whole genome single nucleotide polymorphism based phylogeny of Francisella tularensis and its application to the development of a strain typing assay. BMC Microbiol. 2009; 9: 213.

48. Осин А.В., Краснов Я.М., Гусева Н.П., Смирнова Н.И. Разработка алгоритма MLST-типирования пандемических и предпандемических штаммов Vibrio cholerae биовара эльтор. Проблемы особо опасных инфекций. 2011; 1(107): 58-61.

49. Kotetishvili M., Kreger A., Wauters G., Morris J.G.Jr, Sulakvelidze A., Stine O.C. Multilocus sequence typing for studying genetic relationships among Yersinia species. J. Clin. Microbiol. 2005; 43(6): 2674-84.

50. Kim K., Cheon E., Wheeler K.E., Youn Y., Leighton T.J., Park $\boldsymbol{C}$. et al. Determination of the most closely related bacillus isolates to Bacillus anthracis by multilocus sequence typing. Yale J. Biol. Med. 2005; 78(1): 1-14

51. Sayan M., Yumuk Z., Bilenoglu O., Erdenlig S., Willke A. Genotyping of Brucella melitensis by rpoB gene analysis and reevaluation of conventional serotyping method. Jpn J. Infect. Dis. 2009; 62(2): 160-3.

52. Cariri F.A., Costa A.P., Melo C.C., Theophilo G.N., Hofer E., de Melo Neto O.P. et al. Characterization of potentially virulent non-O1/non-O139 Vibrio cholerae strains isolated from human patients. Clin. Microbiol. Infect. 2010; 16 (1): 62-7.

53. Talkington D., Bopp C., Tarr C., Parsons M.B., Dahourou G., Freeman M. et al. Characterization of toxigenic Vibrio cholerae from Haiti, 2010-2011. Emerg. Infect. Dis. 2011; 17(11): 2122-9.

54. Okinaka R.T., Henrie M., Hill K.K., Lowery K.S., Van Ert M., Pearson T. et al. Single nucleotide polymorphism typing of Bacillus anthracis from Sverdlovsk tissue. Emerg. Infect. Dis. 2008; 14(4): 653-6.

55. Jacob D., Wahab T., Edvinsson B., Peterzon A., Boskani T.,
Farhadi L. et al. Identification and subtyping of Francisella by pyrosequencing and signature matching of $16 \mathrm{~S}$ rDNA fragments. Lett. Appl. Microbiol. 2011; 53(6): 592-5.

56. Hendriksen R.S., Price L.B., Schupp J.M., Gillece J.D., Kaas R.S., Engelthaler D.M. et al. Population genetics of Vibrio cholerae from Nepal in 2010: evidence on the origin of the Haitian outbreak. MBio. 2011; 2(4): e00157-11.

57. Price E.P., Seymour M.L., Sarovich D.S., Latham J., Wolken $\boldsymbol{S} . \boldsymbol{R}$. et al. Molecular epidemiologic investigation of an anthrax outbreak among heroin users, Europe. Emerg. Infect. Dis. 2012; 18(8): 1307-13.

\section{REFERENCES}

1. Yang Y., Wang J., Wen H., Liu H. Comparison of two suspension arrays for simultaneous detection of five biothreat bacterial in powder samples. J. Biomed. Biotechnol. 2012; 2012: 831052.

2. Martynjuk R.A., Sandahchiev L.S., Netesov S.V., Onishhenko G.G. Bioterrorism: national and global threat. Vestnik Rossiyskoy AN. 2003; 3: 195. (in Russian)

3. Sabat A.J., Budimir A., Nashev D., Sá-Leão R., van Dijl Jm, Laurent $\boldsymbol{F}$. et al. Overview of molecular typing methods for outbreak detection and epidemiological surveillance. Euro Surveill. 2013; 18(4): 20380.

4. Breneva N.V., Maramovich A.S., Klimov V.T. The population variability of Yersinia pestis in soil samples from the natural focus of plague. Zhurnal mikrobiologii, jepidemiologii i immunobiologii. 2006; 2: 7-11. (in Russian)

5. Mwansa J.C., Mwaba J., Lukwesa C., Bhuiyan N.A., Ansaruzzaman M., Ramamurthy T. et al. Multiply antibiotic-resistant Vibrio cholerae $\mathrm{O} 1$ biotype El Tor strains emerge during cholera outbreaks in Zambia. Epidemiol. Infect. 2007; 135(5): 847-53.

6. Tenover F.C., Arbeit R.D., Goering R.V., Mickelsen P.A., Murray B.E., Persing $\boldsymbol{D} . \boldsymbol{H}$. et al. Interpreting chromosomal DNA restriction patterns produced by pulsed-field gel electrophoresis: criteria for bacterial strain typing. J. Clin. Microbiol. 1995; 33(9): 2233-9.

7. Smith A.M., Keddy K.H., De Wee L. Characterization of cholera outbreak isolates from Namibia, December 2006 to February 2007. Epidemiol. Infect. 2008; 136(9): 1207-9.

8. Safa A., Bhuiyan N.A., Alam M., Sack D.A., Nair GB. Genomic relatedness of the new Matlab variants of Vibrio cholerae O1 to the classical and El Tor biotypes as determined by pulsed-field gel electrophoresis. J. Clin. Microbiol. 2005; 43(3): 1401-4.

9. Chowdhury N., Asakura M., Neogi S.B., Hinenoya A., Haldar S., Ramamurthy $\boldsymbol{T}$. et al. Development of simple and rapid PCR-fingerprinting methods for Vibrio cholerae on the basis of genetic diversity of the superintegron. J. Appl. Microbiol. 2010; 109(1): 304-12.

10. Li Z.J., Cui B.Y., Chen H., Chen J.D., Zhao H.Y., Piao D.R. et al. Molecular Typing of Brucella Suis Collected from 1960s to 2010 s in China by MLVA and PFGE. Biomed. Environ. Sci. 2013; 26(6): 504-8.

11. Eroshenko G.A., Pavlova A.I., Kukleva L.M., Shavina N.Yu., Kutyrev $\boldsymbol{V} \cdot \boldsymbol{V}$. Genotyping of Yersinia pestis strains on the basis of variation of ribosomal rRNA biosynthesis gene. Zhurnal mikrobiologii, jepidemiologii i immunobiologii. 2007; 3: 6-10 (in Russian).

12. Torrea G., Chenal-Francisque V., Leclercq A., Carniel E. Efficient tracing of global isolates of Yersinia pestis by restriction fragment length polymorphism analysis using three insertion sequences as probes. J. Clin. Microbiol. 2006; 44(6): 2084-92.

13. Fey P.D., Dempsey M.M., Olson M.E., Chrustowski M.S., Engle J.L., Jay J.J. et al. Molecular analysis of Francisella tularensis subspecies tularensis and holarctica. Am. J. Clin. Pathol. 2007; 128(6): 926-35

14. Kantardjiev T., Ivanov I., Velinov T., Padeshki P., Popov B., Nenova R., Mincheff M. Tularemia outbreak, Bulgaria, 19972005. Emerg. Infect. Dis. 2006; 12(4): 678-80.

15. Zhou H., Lou J., Diao B., Cui Z., Pang B., Zhang L. et al. Comparison of amplified fragment length polymorphism and pulsedfield gel electrophoresis for subtyping of Vibrio cholerae serogroups O1 and O139. Foodborne Pathog. Dis. 2011; 8(2): 291-8.

16. Reen F.J., Boyd E.F. Molecular typing of epidemic and nonepidemic Vibrio cholerae isolates and differentiation of V. cholerae 
and V. mimicus isolates by PCR-single-strand conformation polymorphism analysis. J. Appl. Microbiol. 2005; 98(3): 544-55.

17. Eroshenko G.A., Odinokov G.N., Kukleva L.M., Pavlova A.I., Krasnov Y.M., Shavina N.Y. et al. Standard algorithm of molecular typing of Yersinia pestis strains. Zhurnal mikrobiologii, jepidemiologii i immunobiologii. 2012; 3: 25-35. (in Russian)

18. Romanova A.V., Zakharova I.B., Zamaraev V.S., Viktorov D.V. Design of Primers for Detection and Typing of $\beta$-Lactamase Genes from Pathogenic Species of Burkholderia. Problemy osobo opasnyh infekcij. 2012; 2(112): 59-61. (in Russian)

19. Lomov J.M., Telesmanich N.R., Kruglikov V.D., Avdeeva E.P., Ezhova M.I., Shalu O.A. et al. The phenotypic and molecular biological characteristics of Vibrio cholerae El Tor strains isolated from environmental water objects in Rostov-on-Don in 2003-2008. Jepidemiologija i infekcionnye bolezni. 2011; 1: 24-8 (in Russian).

20. Van Ert M.N., Easterday W.R., Simonson T.S., U'Ren J.M., Pearson T., Kenefic L.J. et al. Strain-specific single-nucleotide polymorphism assays for the Bacillus anthracis Ames strain. J. Clin. Microbiol. 2007; 45(1): 47-53.

21. Li Y., Dai E., Cui Y., Li M., Zhang Y., Wu M. et al. Different region analysis for genotyping Yersinia pestis isolates from China. PLoS One. 2008; 3(5): e2166.

22. Duangsonk K., Gal D., Mayo M. et al. Use of a variable amplicon typing scheme reveals considerable variation in the accessory genomes of isolates of Burkholderia pseudomallei. J. Clin. Microbiol. 2006; 44(4): 1323-34.

23. Huber B., Scholz H.C., Lucero N., Busse H.J. Development of a PCR assay for typing and subtyping of Brucella species. Int. J. Med. Microbiol. 2009; 299(8): 563-73.

24. Antonov V.A., Tkachenko G.A., Altukhova V.V., Savchenko S.S., Zinchenko O.V., Viktorov D.V. et al. Molecular identification and typing of Burkholderia pseudomallei and Burkholderia mallei: when is enough enough? Trans. Roy. Soc. Trop. Med. Hyg. 2008; 102 (Suppl. 1): S134-9.

25. Eroshenko G.A. Molecular typing of Vibrio cholerae Non-O1/ Non-O139 strains, isolated from cholera patients in the territory of the Russian Federation and other CIS countries. Problemy osobo opasnyh infekcij. 2005; 2(90): 64. (in Russian)

26. de la Puente-Redondo V.A., del Blanco N.G., Gutiérrez-Martín C.B., García-Peña F.J., Rodríguez Ferri E.F. Comparison of different PCR approaches for typing of Francisella tularensis strains. J. Clin. Microbiol. 2000; 38(3): 1016-22.

27. Shuan Ju Teh C., Thong K.L., Osawa R., Heng Chua K. Comparative PCR-based fingerprinting of Vibrio cholerae isolated in Malaysia. J. Gen. Appl. Microbiol. 2011; 57(1): 19-26.

28. Kingston J.J., Tuteja U., Kapil M., Murali H.S., Batra H.V. Genotyping of Indian Yersinia pestis strains by MLVA and repetitive DNA sequence based PCRs. Antonie v. Leeuwenhoek 2009; 96(3): 303-12.

29. Motin V.L., Georgescu A.M., Elliott J.M., Hu P., Worsham P.L., Ott L.L. et al. Genetic variability of Yersinia pestis isolates as predicted by PCR-based IS100 genotyping and analysis of structural genes encoding glycerol-3-phosphate dehydrogenase (glpD). J. Bacteriol. 2002; 184(4): 1019-27.

30. Larson M.A., Fey P.D., Bartling A.M., Iwen P.C., Dempsey M.P., Francesconi S.C. et al. Francisella tularensis molecular typing using differential insertion sequence amplification. J. Clin. Microbiol. 2011; 49(8): 2786-97.

31. Cui Y., Li Y., Gorgé O., Platonov M.E., Yan Y., Guo Z. et al. Insight into microevolution of Yersinia pestis by clustered regularly interspaced short palindromic repeats. PLoS One. 2008; 3(7): e2652.

32. Platonov M.E., Evseeva V.V., Dentovskaja S.V., Anisimov A.P. Molecular typing of Yersinia pestis. Molekuljarnaja genetika, mikrobiologija i virusologija. 2013; 2: 3-12. (in Russian)

33. Rjazanova A.G., Eremenko E.I., Cygankova O.I., Cygankova E.A., Kulichenko A.N. Application of Bacillus anthracis molecular typing methods by the reference center for the anthrax agent monitoring. Problemy osobo opasnyh infekcij. 2011; 4(110): 68-70. (in Russian)

34. Danin-Poleg Y., Cohen L.A., Gancz, H., Broza Y.Y., Goldshmidt $\boldsymbol{H}$., Malul E. et al. Vibrio cholerae strain typing and phylogeny study based on simple sequence repeats. J. Clin. Microbiol. 2007; 45(3): $736-46$.
35. Vogler A.J., Birdsell D., Wagner D.M., Keim P. An optimized, multiplexed multi-locus variable-number tandem repeat analysis system for genotyping Francisella tularensis. Lett. Appl. Microbiol. 2009; 48(1): 140-4.

36. Kulakov Ju.K., Cirel'son L.E., Zheludkov M.M. Moleculargenetic characterization of canine and rangiferine Brucella isolates from different regions of Russia. Molekuljarnaja genetika, mikrobiologija i virusologija. 2012; 4: 28-33. (in Russian)

37. Vodopjanov A.S., Mishankin B.N., Pavlovich N.V., Pichurina N.L. Genotypic heterogeneity and geographic diversity of collection strains of Francisella tularensis as determined using the VNTR variability analysis and DNA sequencing. Molekuljarnaja genetika, mikrobiologija i virusologija. 2007; 2: 33-40. (in Russian)

38. Onishhenko G.G., Kulichenko A.N., Rjazanova A.G., Demina J.V., Kriga A.S., Eremenko E.I. et al. Analysis of outbreak of anthrax in Omsk region in 2010. Zhurnal mikrobiologii, jepidemiologii i immunobiologii. 2012; 5: 33-6. (in Russian)

39. Lam C., Octavia S., Reeves P.R., Lan R. Multi-locus variable number tandem repeat analysis of 7 th pandemic Vibrio cholerae. BMC Microbiol. 2012; 12: 82

40. Price E.P., Hornstra H.M., Limmathurotsakul D., Max T.L., Sarovich D.S., Vogler A.J. et al. Within-host evolution of Burkholderia pseudomallei in four cases of acute melioidosis. PLoS Pathog. 2010; 6(1): e1000725.

41. Kenefic L.J., Beaudry J., Trim C., Daly R., Parmar R., Zanecki $S$. et al. High resolution genotyping of Bacillus anthracis outbreak strains using four highly mutable single nucleotide repeat markers. Lett. Appl. Microbiol. 2008; 46(5): 600-3

42. Derzelle S., Laroche S., Le Flèche P., Hauck Y., Thierry S., Vergnaud $\boldsymbol{G}$. et al. Characterization of genetic diversity of Bacillus anthracis in France by using high-resolution melting assays and multilocus variable-number tandem-repeat analysis. J. Clin. Microbiol. 2011; 49(12): 4286-92.

43. Winchell J.M., Wolff B.J., Tiller R., Bowen M.D., Hoffmaster A.R. Rapid identification and discrimination of Brucella isolates by use of real-time PCR and high-resolution melt analysis. J. Clin. Microbiol. 2010; 48(3): 697-702.

44. Zaharova I.B., Romanova A.V., Teterjatnikova N.N., Zamaraev V.S., Viktorov D.V. Molecular typing and polymorphism analysis of $\beta$-lactamase genes in pathogenic Burkholderia species. Vestnik Volgogradskogo gosudarstvennogo medicinskogo universiteta. 2012; 2: 98-101. (in Russian)

45. Ciammaruconi A., Grassi S., Faggioni G., De Santis R., Pittiglio V., D'Amelio $R$. et al. A rapid allele variant discrimination method for Yersinia pestis strains based on high-resolution melting curve analysis. Diagn. Microbiol. Infect. Dis. 2009; 65(1): 7-13.

46. Li W., Raoult D., Fournier P. Bacterial strain typing in the genomic era. FEMS Microbiol. Rev. 2009; 33: 892-916.

47. Pandya G.A., Holmes M.H., Petersen J.M., Pradhan S., Karamycheva S.A., Wolcott M.J. et al. Whole genome single nucleotide polymorphism based phylogeny of Francisella tularensis and its application to the development of a strain typing assay. BMC Microbiol. 2009; 9: 213

48. Osin A.V., Krasnov Ja.M., Guseva N.P., Smirnova N.I. Elaboration of the Algorithm of MLST-Typing of Pandemic and PrePandemic V. cholerae El Tor strains. Problemy osobo opasnyh infekcij. 2011; 1(107): 58-61. (in Russian)

49. Kotetishvili M., Kreger A., Wauters G., Morris J.G.Jr, Sulakvelidze A., Stine O.C. Multilocus sequence typing for studying genetic relationships among Yersinia species. J. Clin. Microbiol. 2005; 43(6): 2674-84.

50. Kim K., Cheon E., Wheeler K.E., Youn Y., Leighton T.J., Park $\boldsymbol{C}$. et al. Determination of the most closely related Bacillus isolates to Bacillus anthracis by multilocus sequence typing. Yale J. Biol. Med. 2005; 78(1): 1-14.

51. Sayan M., Yumuk Z., Bilenoglu O., Erdenlig S., Willke A. Genotyping of Brucella melitensis by rpoB gene analysis and reevaluation of conventional serotyping method. Jpn J. Infect. Dis. 2009; 62(2): 160-3.

52. Cariri F.A., Costa A.P., Melo C.C., Theophilo G.N., Hofer E., de Melo Neto O.P. et al. Characterization of potentially virulent 
non-O1/non-O139 Vibrio cholerae strains isolated from human patients. Clin. Microbiol. Infect. 2010; 16 (1): 62-7.

53. Talkington D., Bopp C., Tarr C., Parsons M.B., Dahourou G., Freeman M. et al. Characterization of toxigenic Vibrio cholerae from Haiti, 2010-2011. Emerg. Infect. Dis. 2011; 17(11): 2122-9.

54. Okinaka R.T., Henrie M., Hill K.K., Lowery K.S., Van Ert M., Pearson T. et al. Single nucleotide polymorphism typing of Bacillus anthracis from Sverdlovsk tissue. Emerg. Infect. Dis. 2008; 14(4): 653-6.

55. Jacob D., Wahab T., Edvinsson B., Peterzon A., Boskani T., Farhadi $\boldsymbol{L}$. et al. Identification and subtyping of Francisella by pyrosequencing and signature matching of $16 \mathrm{~S}$ rDNA fragments. Lett. Appl. Microbiol. 2011; 53(6): 592-5.

56. Hendriksen R.S., Price L.B., Schupp J.M., Gillece J.D., Kaas R.S., Engelthaler D.M. et al. Population genetics of Vibrio cholerae from Nepal in 2010: evidence on the origin of the Haitian outbreak. MBio. 2011; 2(4): e00157-11.

57. Price E.P., Seymour M.L., Sarovich D.S., Latham J., Wolken S.R. et al. Molecular epidemiologic investigation of an anthrax out- break among heroin users, Europe. Emerg. Infect. Dis. 2012; 18(8): 1307-13.

Поступила 25.12 .13

\section{Сведения об авторах:}

Савченко Сергей Сергеевич, канд. мед. наук, ст. науч. сотр. лаб. генной диагностики и типирования микроорганизмов, e-mail: dokmop@pochta.ru; Ткаченко Галина Александровна, канд. мед. наук, доцент, зав. лаб. генной диагностики и типирования микроорганизмов, e-mail: tkachenko_g@mail. ru; Абуева Асият Исаевна, мл. науч. сотр. лаб. генной диагностики и типирования микроорганизмов; Муратова Юлия Олеговна, мл. науч. сотр. лаб. генной диагностики и типирования микроорганизмов; Антонов Валерий Алексеевич, доктор мед. наук, проф., директор ФКУз “Волгоградский научно-исследовательский противочумный институт” Роспотребнадзора; e-mail: vari2@sprint-v.com.ru

\title{
МЕДИЦИНСКАЯ ПАРАЗИТОПОГИЯ И ТРОПИЧЕСКИЕ БОИЕЗНИ
}

(С КОЛЛЕКТИВ АВТОРОВ, 2014

УДК 616.5-002.9-036.1

\author{
А.М. Бронштейн ${ }^{1,2}$, Н.А. Малышев ${ }^{2}$, Н.Г. Кочергин ${ }^{1}$, С.Н. Жаров
}

\section{ДЕРМАТОБИАЗ У РОССИЙСКОГО ТУРИСТА, ПОСЕТИВШЕГО АРГЕНТИНУ И БРАЗИЛИЮ Описание случая и обзор литературы}

${ }^{1}$ Первый Московский государственный медицинский университет им. И.М. Сеченова, 119991, Москва, ул. Трубецкая, 8 ;

${ }^{2}$ Инфекционная клиническая больница № 1, 125367, Москва, Волоколамское шоссе, 63;

${ }^{3}$ Российский национальный исследовательский медицинский университет им. Н.И. Пирогова, 125315, Москва, 1-я Курьяновская ул., 34, корп. 3

Описан случай дерматобиаза у туриста, посетивщего Бразилию и Аргентину. Заражение произошло во время экскурсии на водопады Игуасу. Отмечены проблемы в диагностике тропических кожных миазов и методы лечения. Определены факторы риска инфицирования личинками Dermatobia hominis и объективные проблемы в профилактике дерматобиаза.

К л ю ч е в ы е с ло в а : дерматобиаз; глубокий кожный миаз; Dermatobia hominis; mурист; Аргентина; Бразилия; водопады Игуасу.

A.M.Bronshteyn ${ }^{1,2}$, N.A.Malyshev ${ }^{2}$, N.G.Kochergin ${ }^{1}$, S.N.Jarov ${ }^{3}$

DERMATOBIASIS IN A RUSSIAN TOURIST TRAVELLED TO ARGENTINE AND BRAZIL

A CASE AND REVIEW OF THE LITERATURE

${ }^{1}$ I.M. Sechenov First Moscow State Medical University, 119121, Moscow, Russian Federation;

${ }^{2}$ Infectious clinical hospital N1, 119121, Moscow, Russian Federation;

${ }^{3}$ Pigorov Russian National Research Medical University, 119121, Moscow, Russian Federation

A case of furuncular myiasis is presented as a 65-year-old man travelled to Iguaçu Falls in Brazil and Argentine. Furunclelike lesions were observed on the top of his right shoulder blade and he complained of crawling sensations within his shoulder blade. Two invasive larva of botfly, Dermatobia hominis, were extruded from the furuncular lesion of the patient. This condition is endemic to the forested areas of Mexico, Central and South America. Because of widespread travel, furuncular myiasis has become more common in European countries. Awareness of cutaneous myiasis for clinicians should be considered for a patient who has a furuncular lesion and has recently returned from a botfly-endemic area. Misdiagnosis and mismanagement can occur owing to limited awareness of the condition outside endemic areas.

K e y w ord s: furuncular myiasis; tourist; botfly; Dermatobia hominis; Russia; Brazil; Argentine; Iguaçu Falls.

Для корреспонденции: Бронштейн Александр Маркович, 127015 Москва, ул. Писцовая, 10; ГКБ № 24, отделение гельминтологии, e-mail: bronstein@mail.ru 